\title{
Pornography Use and Holistic Sexual Functioning: A Systematic Review of Recent Research K. Camille Hoagland ${ }^{1}$ and Joshua B. Grubbs ${ }^{1}$
}

\begin{abstract}
Purpose of the Review: Pornography use is a common recreational activity in most developed nations with unrestricted internet access. As public awareness of pornography's popularity has grown, so have concerns about potentially deleterious effects of pornography. One domain of particular concern has been the impact of pornography use and online sexual behaviors on sexual well-being. Over recent years, a number of studies have examined how pornography use relates to sexual well-being. The present work seeks to review such literature, with a particular focus on the effects of pornography on sexual functioning and sexual satisfaction. To this end, a systematic review of recent research (within the past 5 years) was conducted.

Recent Findings: A total of 44 articles were included in the systematic review. In some situations, pornography use is associated with greater sexual functioning and greater sexual satisfaction, and in other cases it seems to be associated with lower sexual functioning and lower sexual satisfaction. Specifically, mere pornography use itself was most often not associated with sexual functioning in either direction, but self-reported problematic use of pornography was consistently associated with more sexual functioning problems.
\end{abstract}

Summary: Collectively, results suggest a nuanced understanding of the effects of pornography on sexual well-being, with the context of and perceptions about pornography use being extremely important in predicting whether or not pornography has negative effects.

Keywords: Sexually Explicit Media; Pornography Addiction; Erectile Dysfunction; Behavioral Addiction; Online Sexual Activity

Like most forms of digital entertainment, the quantity of pornography available via the internet has exponentially grown over the past two decades. In 2019 alone, one of the largest pornography streaming websites, Pornhub, amassed a total of 1.36 million hours (169 years) of new pornographic content and 42 billion visits to their website [1]. Alongside this increase in availability, it also seems that pornography use has become more common in the past several decades [2]. Pornography's massive online presence and apparent popularity have not gone unnoticed by critics. Indeed, the ever-growing ubiquity of internet pornography has raised questions in the general population and academic circles about its potential effects on consumers, especially in regard to its impact on sexual dysfunction and satisfaction. In light of this exponential growth in both pornography use and concerns about pornography use's effects on sexual functioning, the goals of the present work are to conduct a systematic review of recent (i.e., within the past 5 years) literature on pornography use and sexual

\footnotetext{
${ }^{1}$ Department of Psychology, Bowling Green State University, Bowling Green, $\mathrm{OH}, 43443$ Correspondence regarding this article should be sent to Joshua B. Grubbs (Grubbsj@BGSU.edu).
} 
functioning, to synthesize key findings, and to provide recommendations for new domains of research.

\section{Sexual Functioning}

For several decades, research on sexual functioning was most often concerned with older men's ability to achieve and maintain erections [3]; however, recent research has taken a more nuanced approach to defining sexual functioning, recognizing sexual functioning as a multifaceted construct applying to all genders and ages. Sexual functioning, as described in current literature, applies to a broad range of people, and it involves a range of sexual responses and outcomes. For example, research about erectile dysfunction (ED) has been extended to younger men in more recent years, and orgasm functioning for both men and women is also regularly studied, including research on ability to reach climax as well as experiences with premature or delayed ejaculation and orgasm [4].

Moving away from understanding sexual functioning in terms of erectile abilities alone has also allowed for a greater exploration of subjective perceptions of sexual experiences, especially sexual satisfaction. Sexual satisfaction has been conceptualized as the subjective evaluation of the components of an individual's sexual life and the cognitive, psychological, and/or physiological responses to them [5-7]. Higher sexual satisfaction is associated with lower rates of sexual dysfunctions [8], and has been shown to be a key component in sexual wellbeing [9].

\section{Pornography use and Sexual Functioning}

Research relevant to pornography use has expanded greatly in recent years [10]. Much of this research has been related to sexual motivation [11], compulsive sexual behavior [12], and sexual practices [13]. In the majority of cases, it seems, pornography use is a largely recreational activity that occurs with few, if any, negative consequences for users. Yet, concerns about potentially deleterious effects are quite publicized, and public health researchers have noted increasing patterns of concern about the sexual health implications of widespread pornography use [14].

As research related to sexual functioning and research related to pornography use have independently expanded over recent years, there has also been increased interest in the effects that pornography use has on sexual functioning. Much of this interest has occurred in the public domain as parts of larger debates about pornography use more broadly. For example, information available online from antipornography websites geared toward (typically male) lay audiences warns of the dangers of pornography, emphasizing the belief that pornography destroys sex lives. Personal accounts on such websites describe the adverse effects of pornography in detail, explaining that pornography use causes dissatisfaction with "normal" sex and realworld partners, mechanical and unloving dyadic sexual encounters, and issues with sexual performance and erectile dysfunction $[15,16]$. Despite these claims, empirical research, to date, has not found compelling evidence that pornography use is related to sexual dysfunction $[17 \bullet \bullet]$.

Recent reviews have outlined evidence suggesting that pornography use may negatively impact an individual's sexual wellbeing, which included sexual 
dysfunctions, in addition to anxiety surrounding one's sexual performance and compulsive pornography use [18]. However, this review also provided numerous examples of positive effects of pornography use on the quality of an individual's sexual life, some of which are directly contradictory to the negative effects already described, such as using pornography to reduce anxiety in sexual encounters and increasing women's sexual satisfaction.

These findings suggest that the literature currently does not describe consistent findings about pornography's potential impact on sexual wellbeing. Even so, public messaging about pornography tends to be negative, without any mention of positive effects, as these messages typically originate from anti-pornography outlets $[19,20]$. This discrepancy between public messages from activist communities and empirical claims in published literature suggests that there is a disconnect between what is actually known about the impact of pornography on sexual health and what is publicly believed about pornography's impact on sexual health. The present review seeks to understand these discrepancies by approaching the topic from a perspective that emphasizes holistic sexual wellbeing that extends beyond physiological sexual functioning alone and also incorporates psychosocial aspects of sexual functioning, such as sexual satisfaction.

\section{Method}

Based on the above discussed literature, the primary purpose of the present work was to conduct a systematic review of recently published literature that examines the relationships between pornography use and sexual functioning, broadly defined.
Below, we describe the methodology that guided this systematic review.

\section{Procedure}

In service of the above aims, we conducted a systematic review of empirical literature published on pornography use and sexual functioning published between January $1^{\text {st }}, 2016$, and May 1st, 2021. We conducted primary searches on PubMed, PsycInfo, and Academic Search Complete. Search terms included "pornography," "online sexual behavior," "cybersex," or "porn*" in combination with one or more of the following terms: "dysfunction," "erectile," "sexual functioning," "sexual function," "erectile dysfunction," "sexual satisfaction," "sexual dysfunction," "erection," "anorgasmia," "vaginisimus," "arousal disorder," "desire disorder," "pain disorder," and "orgasm disorder." We supplemented these queries with additional searches via Google Scholar and by consulting with other experts on pornography and sexual health to identify any studies that had been previously missed (2 studies identified). We excluded qualitative studies that lacked quantitative or empirical components, case reports or case studies, theoretical reviews, and previous reviews or meta-analyses on these topics. We also excluded studies that only focused on outcomes like relationship satisfaction, without including findings about sexual satisfaction. The results of this process are summarized in Figure 1.

A total of 114 studies were identified that met the inclusion criteria after reading the title and abstract. After reviewing the studies, 44 were relevant to the present review. Of these, 43 (97.7\%) included at least one measure of psychosocial sexual 
functioining, which was most often a measure of sexual satisfaction, and 12 studies (27.2\%) measured physiological sexual responses, including outcomes related to sexual arousal, orgasm, and ED.

\section{Results}

Results revealed a number of key findings and themes, below we review these findings and themes, beginning with a description of sampling methods, and then moving on into a summary of key findings.

\section{Demographics and methodologies of studies}

There appears to be increasing interest in the effects of pornography on sexual functioning over recent years. Among included studies, 5 were published in 2016, 6 in both 2017 and 2018. 12 in 2019, 10 in 2020, and 5 have been published thus far in 2021. Collectively, this pattern is preliminary evidence for an accelerating trend of interest in this topic.

Over one-third of the studies included in this review used samples from the United States (34.1\%). Additional samples were taken from Canada (15.9\%), Hungary (11.4\%), Croatia (6.8\%), Poland (4.5\%), Australia (4.5\%), the U.K. (4.5\%), Germany (4.5\%), Spain $(4.5 \%)$. One study drew from a multinational sample [21], and one study was conducted in each of the following countries: Belgium, the Czech Republic, France, Portugal, South Korea. Regarding sample characteristics, age was reported in 43 (97.7\%) studies. Two studies were specific to adolescents [22,23], while the remaining 41 that reported age focused on adult samples. Nearly all studies reported the gender of their sample $(k=43)$, with five studies focusing specifically on men, but only one focused specifically on women [24]. Most studies reported sexual orientation $(k=32)$, with 12 of these studies' samples comprised of only heterosexual participants, while the remaining studies included individuals who engaged in same-sex relations to some degree (e.g., homosexual, homosexual with heterosexuality to some extent, bisexual, etc.; $k=20)$. In addition, $38(86.4 \%)$ studies reported relationship characteristics of their samples. Fourteen (31.8\%) samples consisted of participants in committed relationships, whereas the remaining included a variety of relationship statuses, including being single.

\section{Pornography Use and Self-Reported Physiological Sexual Functioning}

Few studies assessed the relationship between pornography use and physiological sexual functioning (i.e., erectile functioning, ability to achieve orgasm, sexual arousal, etc.; $k=12$ ). Of these, one had an entirely female sample [24], another two had entirely male samples, and the others were a mix of both men and women. Findings from these studies varied. Some indicated that pornography use may have a negative impact on physiological sexual functioining, which included needing longer stimulation and more sexual stimuli to reach orgasm [25] and needing to fantasize about pornography during partnered sexual activities to maintain sexual arousal for men specifically [26].

Importantly, some studies noted seemingly positive effects of pornography use on physiological sexual functioining. For example, one study found that engagement in isolated online sexual activities (including masturbation to pornography) was associated with better sexual functioning [27]. In addition, partnered pornography use was 
associated with higher sexual arousal for monogamous couples [28] and for women [29,30]. Regarding women specifically, pornography use was also associated with enhanced sexual arousal during solo masturbation [24], while other studies noted that pornography use had no effect on women's sexual functioning at all [31]. Among men, those who reported using pornography to explore their sexual curiosity appear more likely to experience higher levels of physiological sexual functioining than those who use pornography to avoid negative emotional states [29].

Three studies looked at the difference between the effects of self-reported problematic pornography use and frequency of pornography use on physiological sexual functioning. One of these studies [32••] measured self-reported problematic pornography use via six factors traditionally associated with addiction (salience, tolerance, mood modification, conflict, withdrawal, and relapse). Results indicated that self-reported problematic pornography use had a moderate, negative relationship with physiological sexual functioning for both men and women, whereas frequency of pornography use had a weaker, positive association with physiological sexual functioning for both men and women. That is, both frequency of pornography use and self-reported problematic pornography use did relate to functioning, but in opposite ways. In contrast, another study found that more compulsive users of pornography with low-to-moderate distress over their use (i.e., people who report excessive pornography use, and feel that their use is out of control, but do not report high levels of guilt or

\footnotetext{
2 This particular study assessed problematic online sexual activities broadly, but found that over $90 \%$ of the sample was referring to pornography use when
}

shame over their use) reported very low levels of physiological sexual functioning problems in comparison to infrequent but highly distressed users [33].

In one empirical study examining links between pornography use and erectile functioning [17••], self-reported problematic pornography use, as measured by feelings of loss of control, was consistently associated with reports of erectile dysfunction (both cross-sectionally and longitudinally), but frequency of pornography use was not consistently associated with erectile dysfunction. Additionally, findings revealed that religiousness and moral incongruence over pornography use (i.e., moral opposition to pornography combined with continued pornography use) were highly correlated with self-reported problematic pornography use.

Another study found that pornography use combined with masturbation was associated with higher rates of erectile dysfunction [31]. Findings also indicated that the lowest rates of erectile dyfunction were associated with having a preference for partnered sex without pornography. Rates of erectile dysfunction increased significantly when pornography use was preferred over partnered sex. Finally, additional research in a multi-national European sample [21] suggests that men's self-reported problematic pornography use ${ }^{2}$ (e.g., loss of control, negative impact, cognitive preoccupation) is robustly related to lower levels of erectile functioning crosssectionally.

\section{Pornography Use and Psychosocial Sexual Functioning}

describing or responding to questions about their online sexual activities. 
In considering a holistic view of sexual functioning, the second major category of findings in recently published literature were those related to psychosocial sexual functioning, largely measured via sexual satisfaction. Similar to findings discussed above, results varied. Some studies found that there was a negligible relationship, or none at all, between pornography use and sexual satisfaction for adult pornography users [24,25,34-37]. Additionally, a longitudinal study of adolescent boys found no relationship between pornography use and sexual satisfaction at baseline or over time [22].

Findings also indicated that there may be beneficial effects of pornography use on sexual satisfaction in some cases. For example, among men, the use of pornography for sexual curiosity related motives was positively linked to greater sexual satisfaction [29]. Similarly, women seem less likely to report problematic pornography use and more likely to report higher sexual satisfaction associated with their pornography use than men [33]. Additional findings showed that, in heterosexual relationships, the female partner's use of pornography was associated with higher sexual desire $[38,39]$ greater sexual satisfaction $[30,40]$, and more frequent engagement in sexual encounters with their partner[29,30]. In addition, for both men and women, some studies have found that watching pornography with a partner was associated with higher sexual satisfaction [28,33].

Despite the above findings, a number of studies did find negative links between pornography use and sexual satisfaction, most often associated with specific contexts of pornography use. Regarding adolescents, although one study has shown that adolescents' sexual satisfaction is not negatively affected by their pornography use [22], another showed that there may be an indirect relationship between these two variables wherein pornography is associated

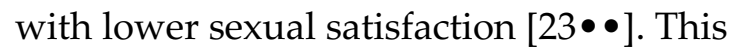
indirect pathway revealed that higher pornography use was related to increased sexually dominant behaviors, which distanced adolescents from their partners, and, in turn, reduced their sexual satisfaction. In regards to adults, prior research has found that those who do not use pornography report the highest sexual satisfaction, particularly surrounding their satisfaction with their sexual partner and the amount of sexual activity they regularly engage in [41]. Although we reviewed evidence above suggesting that using pornography with a partner increases partnered sexual functioning, other research has shown that most pornography users typically consume pornography for the purposes of solitary masturbation, which is associated with decreased sexual satisfaction for both men and women [42-46]. Similarly, it seems that pornography is, at times, associated with preferences for pornographylike sexual encounters, which is, in turn, associated with lower sexual satisfaction [46].

Relationship dynamics may also play an important role in describing the interaction between pornography use and sexual satisfaction. In a sample of same and mixed-sex couples, solitary use of pornography on days of sexual intimacy with their partner was associated with higher sexual distress for their partner [30]. Among heterosexual relationships, pornography use by the male partner was related to lower sexual desire and sexual satisfaction for the female partner [38,39]. Greater pornography 
use discrepancies between partners was also associated with lower sexual desire for the female partner [47]. Research has also demonstrated that, for individuals currently in romantic relationships, experiencing guilt over using pornography was associated with having lower sexual desire for one's own partner, but pornography use itself was not associated with sexual desire [48].

Regarding men specifically, pornography use was associated with lower levels of their own sexual satisfaction $[26,38,45,49]$, especially when they reported problematic pornography use $[33,50]$ or used pornography to avoid negative emotions $[29 \bullet \bullet]$. Frequency of masturbation was indirectly related to men's sexual satisfaction, whereby more frequent masturbation was related to having a preference for porn-like sex, which was negatively associated with sexual satisfaction [43].

Several other contextual factors have been elucidated by prior studies as well. For example, pornography use in the context of religious belief is associated with diminished sexual satisfaction for men [51] as well as women [52]. These studies demonstrated that religious individuals who used pornography reported lower sexual satisfaction than their pornography-using secular counterparts, regardless of the amount of pornography used. In addition, pornography use was indirectly and negatively associated with sexual satisfaction through self-perceived addiction to pornography and sexual dysfunction in one study [53]. Another demonstrated that attachment styles may explain this relationship, such that pornography use had no effect on sexual satisfaction for the securely attached, a negative effect for those with anxious or avoidant attachment, and a positive effect on those with fearful attachment [54].
Frequency of pornography use was also directly related to sexual satisfaction outcomes. In some studies, lower sexual satisfaction was associated with frequency of pornography use, such that pornography use was not associated with sexual satisfaction unless it was used with regularity (more than once per month), with this relationship becoming more negative as frequency of use increased [44,45,55].

To add to the complexity of the relationship between pornography use and sexual satisfaction, additional works have found that sexual satisfaction often interacts with pornography use when predicting other salient outcomes. For example, one study found that pornography use frequency was more strongly associated with the belief that one's own pornography use is out of control when sexual satisfaction was lower [56]. That is, there seem to be interactions between sexual satisfaction and pornography use in predicting self-reported problems with pornography use. Another study found that the relationship between pornography use and couple satisfaction was mediated by sexual satisfaction, and that these relationships were moderated by moral incongruence over pornography use [35], with pornography use being largely unrelated to sexual satisfaction for people who do not morally disapprove of pornography but robustly and negatively related to sexual satisfaction among those that do.

One study [57] examined whether diminished sexual satisfaction might also predict predict pornography use. This study concluded that neither frequency of pornography use nor self reported problems with pornography use were associated with motivation to use pornography due to lack of sexual satisfaction. However, motivation to 
use pornography because of a lack of sexual satisfaction was positively associated with all other motivators for pornography use explored in this study, including sexual pleasure, sexual curiosity, emotional distraction/suppression, stress reduction, boredom avoidance, fantasies, and selfexploration, indicating that sexual dissatisfaction on its own may not be a sufficient motivator for pornography use [57]. Similarly, the only study with a sample of older adults (Mage $=61.61, \mathrm{SD}=7.94$ ), indicated that older men and women use the internet for a variety of sexual purposes, including pornography use, but level of sexual satisfaction was not a motivating factor in using internet pornography [58]. Instead, level of education for men, lower health status for women, and frequency of masturbation for both men and women, were predictive of older adults' use of pornography. In short, although using pornography due to sexual dissatisfaction is an identifiable motive for use, it does not seem to be related to actual levels of use when other motives are also considered.

\section{Discussion}

At the outset of this work, we proposed a systematic review of the links between pornography consumption and holistic sexual functioning in literature published between Jan 1 ${ }^{\text {st }}, 2016$ and May $1^{\text {st }}$, 2021. Below, we summarize these findings, discuss their implications, and propose new avenues for research.

Over the past five years, a number of empirical papers have examined how pornography use may impact overall sexual wellbeing. Consistent with broader trends in research about compulsive sexual behavior [12], research in this domain appears to be increasing at an accelerating rate. In contrast with research about compulsive sexual behavior more generally, the majority of research related to pornography use and sexual functioning has taken place outside of the United States, suggesting global interest in the effects of pornography use. Even so, almost all included studies were conducted in Western countries, hampering generalizability of findings. Additionally, although much of the work conducted in recent years has been cross-sectional in nature, a few studies have examined pornography use and sexual functioning longitudinally.

Across studies, many conflicting findings were evident. There is relatively robust evidence that mere pornography use is likely not related to physiological sexual functioning. That is, there is little evidence that pornography use is driving an epidemic of erectile dysfunction, anorgasmia, or similar conditions often touted by antipornography advocacy groups. In fact, in at least one study, there was evidence that greater pornography use was related to greater self-reported physiological sexual functioning for men and women [32••]. Yet, many of these same studies did find consistent links between self-reported problematic pornography use and physiological sexual functioning. That is, whereas the quantity of pornography consumed seemed to be unrelated to physiological problems in sexual functioning, having feelings of being out of control in or addicted to pornography use was consistently related to greater problems in physiological sexual functioning. In contrast, however, at least one study found that individuals who used pornography excessively and reported feeling that their use was out of control demonstrated the 
highest levels of physiological sexual functioning in comparison to recreational pornography users and individuals who rarely used but found their use distressing [25].

With regards to psychosocial sexual functioning, or, more specifically, sexual satisfaction, conflicting findings were again present. In some studies, pornography use was associated with lower levels of sexual satisfaction, particularly for men. However, these associations seemed to be moderated by a number of factors. In the context of heterosexual relationships, there is clear evidence of pornography use being associated with lower sexual satisfaction for men. Similarly, in some studies, pornography use in women is associated with lower sexual satisfaction. However, in some cases, these links between pornography use and lower sexual satisfaction seem to be moderated by religiousness and moral disapproval of pornography. More specifically, some studies found that those who use pornography while disapproving of it show strong links between use and lower sexual satisfaction, while those who use without disapproving of pornography do not show such associations. These findings are consistent with recent works showing that moral incongruence (i.e., using pornography when one morally disapproves of pornography) is an important consideration when studying pornography $[59,60]$.

\section{Implications}

The present body of work suggests that the use of pornography does not have straightforward or simple effects on sexual functioning. In contrast to narratives put forth by both anti-pornography activists (i.e., that pornography is universally a threat to sexual functioning) and more propornography positions (i.e., that pornography is never a cause of sexual dysfunction), the present state of empirical literature suggests that pornography's effects are varied and heavily influenced by the context of the use.

For individuals who are distressed about their pornography use [33] or who find their use to be out of control $[17 \bullet \bullet, 32 \bullet \bullet]$, pornography use is consistently related to lower levels of physiological sexual functioning. Even so, one study did find that individuals reporting high levels of compulsivity in their use of pornography but only moderate levels of distress about pornography use were actually less likely than recreational users or highly distressed users to report problems in physiological sexual functioning [33]. Such a finding suggests the possibility that distress about pornography use may be more important than dysregulation in use in accounting for problems associated with pornography use. In each of the above studies, frequency of pornography use was generally unrelated to negative outcomes, suggesting that selfperceptions regarding pornography use may be the key element in predicting physiological sexual-functioning problems associated with pornography use.

Similar nuances also emerged in findings related to sexual satisfaction, with recent studies showing that motivations for pornography use differentially predicted sexual satisfaction $[29 \bullet \bullet]$. Similarly, while a number of studies showed that women's pornography use was associated with greater sexual satisfaction for women, some studies found the opposite. Still others found that religion moderated these links so that more religious women did not show positive associations between pornography use and 
sexual satisfaction. To further complicate matters, others showed that, while women's use of pornography was associated with lower personal sexual satisfaction, it was also associated with higher sexual satisfaction in couples.

Ultimately, these findings suggest that, like many human behaviors, the context of pornography use behaviors likely has as much to do with the outcomes of those behaviors as the actual behaviors themselves. For individuals who have more open sexual values or who do not find pornography to be a morally objectionable activity, it seems that pornography use is unlikely to be associated with negative outcomes in sexual functioning. However, for those who are distressed by their use, who consider themselves dysregulated or addicted in their use, who find pornography to be objectionable, or who identify with religious teachings that prohibit pornography, pornography use is often quite robustly associated with problematic outcomes. Collectively, these findings point to the importance of accounting for participants' personal evaluations of pornography when conducting pornography related research. Analyses seeking to determine the direct effects of pornography itself inevitably run the risk of oversimplifing complex links that are moderated by personal beliefs, ideas, and evaluations.

These findings may also point to the importance of understanding the moral context of pornography use. As prior works have repeatedly concluded [61-63], moral disapproval of pornography seems to be an important variable to understand when predicting negative outcomes based on pornography use itself. That is, there is consistent evidence that moral incongruence in pornography use (i.e., using pornography while disapproving of it), predicts a wide range of concerning outcomes, ranging from self-reports of addiction, to relationship conflicts, to-as we review in this paperlower levels of overall sexual functioning. Although some works have questioned the role of this moral incongruence in predicting addiction to pornography $[64,65]$, the broader picture suggested by these findings is that pornography problems due to moral incongruence are likely prevalent in multiple life domains. Accordingly, future research seeking to understand both the positive and the deleterious effects of pornography should likely account for participants' moral evaluations of pornography use.

\section{Conclusion}

Pornography use is and will likely remain a common recreational activity. Despite this popularity, it is also controversial in both public and academic spheres. A number of studies in recent years have examined the links between such use and sexual functioning. In general, the relationships between pornography use and sexual functioning are complex, often being moderated by variables such as religiousness, gender, sexual orientation, moral beliefs, and relationship status. Accordingly, although there is robust evidence that pornography is indeed related to sexual functioning, we find that there is little evidence for simplistic narratives in public or scientific spheres that describe pornography use as universally good or bad for sexual functioning outcomes.

\section{References}

1. The 2019 Year in Review - Pornhub Insights. In: Pornhub [Internet]. 11 Dec 2019 [cited 19 Jun 2020]. Available: 
https://www.pornhub.com/insights/201 9-year-in-review

2. Price J, Patterson R, Regnerus M, Walley $\mathrm{J}$. How much more $\mathrm{xxx}$ is generation $\mathrm{x}$ consuming? Evidence of changing attitudes and behaviors related to pornography since 1973. J Sex Res. 2016;53: 12-20.

doi:10.1080/00224499.2014.1003773

3. Nguyen HMT, Gabrielson AT, Hellstrom WJG. Erectile Dysfunction in Young Men-A Review of the Prevalence and Risk Factors. Sex Med Rev. 2017;5: 508-520. doi:10.1016/j.sxmr.2017.05.004

4. Weinberger JM, Houman J, Caron AT, Anger J. Female Sexual Dysfunction: A Systematic Review of Outcomes Across Various Treatment Modalities. Sex Med Rev. 2019;7: 223-250. doi:10.1016/j.sxmr.2017.12.004

5. Lawrance K, Byers ES. Development of the interpersonal exchange model of sexual satisfaction in long term relationships. Can J Hum Sex. 1992;1: 123-128.

6. Meston C, Trapnell P. ORIGINAL RESEARCH-OUTCOMES ASSESSMENT: Development and Validation of a Five-Factor Sexual Satisfaction and Distress Scale for Women: The Sexual Satisfaction Scale for Women (SSS-W). J Sex Med. 2005;2: 66-81. doi:10.1111/j.1743-

6109.2005.20107.x

7. Philippsohn S, Hartmann U. Determinants of Sexual Satisfaction in a Sample of German Women. J Sex Med.
2009;6: 1001-1010. doi:10.1111/j.17436109.2008.00989.x

8. Dundon CM, Rellini AH. More than Sexual Function: Predictors of Sexual Satisfaction in a Sample of Women Age 40-70. J Sex Med. 2010;7: 896-904. doi:10.1111/j.1743-6109.2009.01557.x

9. Sánchez-Fuentes $M$ del M, SantosIglesias P, Sierra JC. A systematic review of sexual satisfaction. Int J Clin Health Psychol. 2014;14: 67-75. doi:10.1016/S1697-2600(14)70038-9

10. Grubbs JB, Kraus SW. Pornography Use and Psychological Science: A Call for Consideration. Curr Dir Psychol Sci. 2021; 096372142097959. doi:10.1177/0963721420979594

11. Grubbs JB, Wright PJ, Braden AL, Wilt JA, Kraus SW. Internet pornography use and sexual motivation: A systematic review and integration. Ann Int Commun Assoc. 2019;43: 117-155. doi:10.1080/23808985.2019.1584045

12. Grubbs JB, Hoagland KC, Lee BN, Grant JT, Davison P, Reid RC, et al. Sexual addiction 25 years on: A systematic and methodological review of empirical literature and an agenda for future research. Clin Psychol Rev. 2020;82: 101925. doi:10.1016/j.cpr.2020.101925

13. Peter J, Valkenburg PM. Adolescents and pornography: A review of 20 years of research. J Sex Res. 2016;53: 509-531. doi:10.1080/00224499.2016.1143441

14. Nelson KM, Rothman EF. Should public health professionals consider pornography a public health crisis? Am 
J Public Health. 2020;110: 151-153. doi:10.2105/AJPH.2019.305498

15. Fernandez DP, Kuss DJ, Griffiths MD. Short-term abstinence effects across potential behavioral addictions: A systematic review. Clin Psychol Rev. 2020; 101828.

doi:10.1016/j.cpr.2020.101828

16. Imhoff R, Zimmer F. Men's Reasons to Abstain from Masturbation May Not Reflect the Conviction of "reboot" Websites. Arch Sex Behav. 2020;49: 1429-1430. doi:10.1007/s10508-02001722-x

17. • Grubbs JB, Gola M. Is pornography use related to erectile functioning? Results from cross-sectional and latent growth curve analyses. J Sex Med. 2019;16: 111-125. doi:10.1016/j.jsxm.2018.11.004. Provides a multi-sample cross-sectional and longitudinal examination of the links between pornography use frequency, feelings of addiction to pornography, and self-reported erectile functioning.

18. Mollaioli D, Sansone A, Romanelli F, Jannini EA. Sexual Dysfunctions in the Internet Era. In: Jannini EA, Siracusano A, editors. Sexual Dysfunctions in Mentally Ill Patients. Cham: Springer International Publishing; 2018. pp. 163172. doi:10.1007/978-3-319-68306-5_15

19. Burke K, MillerMacPhee A.

Constructing Pornography Addiction's Harms in Science, News Media, and Politics. Soc Forces. 2020; soaa035. doi:10.1093/sf/soaa035
20. Thomas JN. Outsourcing moral authority: The internal secularization of evangelicals' anti-pornography narratives. J Sci Study Relig. 2013;52. doi:10.1111/jssr.12052

21. Wéry A, Billieux J. Online sexual activities: An exploratory study of problematic and non-problematic usage patterns in a sample of men. Comput Hum Behav. 2016;56: 257-266. doi:10.1016/j.chb.2015.11.046

22. Milas $G$, Wright $P$, Štulhofer A. Longitudinal Assessment of the Association Between Pornography Use and Sexual Satisfaction in Adolescence. J Sex Res. 2020;57: 16-28. doi:10.1080/00224499.2019.1607817

23.• Wright PJ, Herbenick D, Paul B, Tokunaga RS. Exploratory Findings on U.S. Adolescents' Pornography Use, Dominant Behavior, and Sexual Satisfaction. Int J Sex Health. 2021;0: 1-7. doi:10.1080/19317611.2021.1888170.

Using a subset of a U.S. nationally representative probability sample, this work provides a careful analysis of how pornography use may lead to sexual behaviors that ultimately reduce sexual satisfaction among adolescents.

24. McNabney SM, Hevesi K, Rowland DL. Effects of Pornography Use and Demographic Parameters on Sexual Response during Masturbation and Partnered Sex in Women. Int J Environ Res Public Health. 2020;17. doi:10.3390/ijerph17093130

25. Dwulit AD, Rzymski P. Prevalence, Patterns and Self-Perceived Effects of Pornography Consumption in Polish 
University Students: A Cross-Sectional Study. Int J Environ Res Public Health. 2019;16. doi:10.3390/ijerph16101861

26. Sun C, Bridges A, Johnson JA, Ezzell MB. Pornography and the male sexual script: An analysis of consumption and sexual relations. Arch Sex Behav. 2016;45: 983-994. doi:10.1007/s10508014-0391-2

27. Barrada JR, Ruiz-Gómez P, Correa AB, Castro Á. Not all Online Sexual Activities Are the Same. Front Psychol. 2019;10. doi:10.3389/fpsyg.2019.00339

28. Rodrigues DL, Lopes D, Dawson K, de Visser R, Štulhofer A. With or Without You: Associations Between Frequency of Internet Pornography Use and Sexual Relationship Outcomes for (Non)Consensual (Non)Monogamous Individuals. Arch Sex Behav. 2020. doi:10.1007/s10508-020-01782-z

29. • Bőthe B, Vaillancourt-Morel M-P, Bergeron S. Associations Between Pornography Use Frequency, Pornography Use Motivations, and Sexual Wellbeing in Couples. J Sex Res. 2021;0: 1-15. doi:10.1080/00224499.2021.1893261.

Provides an empirical investigation of the effects of pornography use and motives for pornography use on the sexual functioning of couples, including sexual satisfaction outcomes.

30. Vaillancourt-Morel M-P, Rosen NO, Štulhofer A, Bosisio M, Bergeron S. Pornography Use and Sexual Health among Same-Sex and Mixed-Sex Couples: An Event-Level Dyadic
Analysis. Arch Sex Behav. 2021;50: 667681. doi:10.1007/s10508-020-01839-z

31. Berger JH, Kehoe JE, Doan AP, Crain DS, Klam WP, Marshall MT, et al. Survey of Sexual Function and Pornography. Mil Med. 2019;184: 731737. doi:10.1093/milmed/usz079

32. • Bőthe B, Tóth-Király I, Griffiths MD, Potenza MN, Orosz G, Demetrovics Z. Are sexual functioning problems associated with frequent pornography use and/or problematic pornography use? Results from a large community survey including males and females. Addict Behav. 2021;112: 106603. doi:10.1016/j.addbeh.2020.106603. Provides an in-depth examination of the differences between problematic pornography use and pornography use frequency in predicting sexual functioning in both men and women.

33. Vaillancourt-Morel M-P, Blais-Lecours S, Labadie C, Bergeron S, Sabourin S, Godbout N. Profiles of Cyberpornography Use and Sexual Well-Being in Adults. J Sex Med. 2017;14: 78-85. doi:10.1016/j.jsxm.2016.10.016

34. Pepping CA, Cronin TJ, Lyons A, Caldwell JG. The Effects of Mindfulness on Sexual Outcomes: The Role of Emotion Regulation. Arch Sex Behav. 2018;47: 1601-1612. doi:10.1007/s10508017-1127-x

35. French IM, Hamilton LD. Male-centric and female-centric pornography consumption: Relationship with sex life and attitudes in young adults. J Sex 
Marital Ther. 2018;44: 73-86. doi:10.1080/0092623X.2017.1321596

36. Minarcik J, Wetterneck CT, Short MB. The effects of sexually explicit material use on romantic relationship dynamics. J Behav Addict. 2016;5: 700-707. doi:10.1556/2006.5.2016.078

37. Bőthe B, Tóth-Király I, Demetrovics Z, Orosz G. The pervasive role of sex mindset: Beliefs about the malleability of sexual life is linked to higher levels of relationship satisfaction and sexual satisfaction and lower levels of problematic pornography use. Personal Individ Differ. 2017;117: 15-22. doi:10.1016/j.paid.2017.05.030

38. Willoughby BJ, Leonhardt ND, Augustus RA. Associations Between Pornography Use and Sexual Dynamics Among Heterosexual Couples. J Sex Med. 2021;18: 179-192. doi:10.1016/j.jsxm.2020.10.013

39. Willoughby BJ, Leonhardt ND. Behind Closed Doors: Individual and Joint Pornography Use Among Romantic Couples. J Sex Res. 2020;57: 77-91. doi:10.1080/00224499.2018.1541440

40. Brown CC, Carroll JS, Yorgason JB, Busby DM, Willoughby BJ, Larson JH. A common-fate analysis of pornography acceptance, use, and sexual satisfaction among heterosexual married couples. Arch Sex Behav. 2017;46: 575-584.

41. Gutiérrez-Puertas L, Hernández VM, Gutiérrez-Puertas V, Granados-Gámez G, Rodríguez-García MC, AguileraManrique G. Online sexual activities among university students: relationship with sexual satisfaction. An Psicol Psychol. 2020;36: 166-172.

42. Emmers-Sommer TM. Reasons for Pornography Consumption: Associations with Gender, Psychological and Physical Sexual Satisfaction, and Attitudinal Impacts. Sex Cult. 2018;22: 48-62. doi:10.1007/s12119-017-9452-8

43. Miller DJ, McBain KA, Li WW, Raggatt PTF. Pornography, preference for pornlike sex, masturbation, and men's sexual and relationship satisfaction. Pers Relatsh. 2019;26: 93-113. doi:10.1111/pere.12267

44. Wright PJ, Bridges AJ, Sun C, Ezzell M, Johnson JA. Personal pornography viewing and sexual satisfaction: A quadratic analysis. J Sex Marital Ther. 2017;0: 00-00. doi:10.1080/0092623X.2017.1377131

45. Wright PJ, Steffen NJ, Sun C. Is the Relationship Between Pornography Consumption Frequency and Lower Sexual Satisfaction Curvilinear? Results From England and Germany. J Sex Res. 2019;56: 9-15. doi:10.1080/00224499.2017.1347912

46. Wright PJ, Paul B, Herbenick D, Tokunaga RS. Pornography and Sexual Dissatisfaction: The Role of Pornographic Arousal, Upward Pornographic Comparisons, and Preference for Pornographic Masturbation. Hum Commun Res. 2021;47: 192-214. doi:10.1093/hcr/hqab001

47. Willoughby BJ, Carroll JS, Busby DM, Brown CC. Differences in pornography 
use among couples: Associations with satisfaction, stability, and relationship processes. Arch Sex Behav. 2016;45: 145158. doi:10.1007/s10508-015-0562-9

48. Bennett M, LoPresti BJ, McGloin R, Denes A. The Desire for Porn and Partner?: Investigating the Role of Scripts in Affectionate Communication, Sexual Desire, and Pornography Consumption and Guilt in Young Adults' Romantic Relationships. West J Commun. 2019;83: 647-667. doi:10.1080/10570314.2018.1564934

49. Leonhardt ND, Willoughby BJ. Pornography, provocative sexual media, and their differing associations with multiple aspects of sexual satisfaction. J Soc Pers Relatsh. 2019;36: 618-641. doi:10.1177/0265407517739162

50. Kowalewska E, Kraus SW, LewStarowicz M, Gustavsson K, Gola M. Which dimensions of human sexuality are related to compulsive sexual behavior disorder (CSBD)? Study using a multidimensional sexuality questionnaire on a sample of polish males. J Sex Med. 2019. doi:10.1016/j.jsxm.2019.05.006

51. Perry SL, Whitehead AL. Only Bad for Believers? Religion, Pornography Use, and Sexual Satisfaction Among American Men. J Sex Res. 2019;56: 5061. doi:10.1080/00224499.2017.1423017

52. Cranney S, Štulhofer A. “Whosoever looketh on a person to lust after them": Religiosity, the use of mainstream and nonmainstream sexually explicit material, and sexual satisfaction in heterosexual men and women. J Sex
Res. 2017;54: 694-705.

doi:10.1080/00224499.2016.1216068

53. Blais-Lecours S, Vaillancourt-Morel M-

$\mathrm{P}$, Sabourin S, Godbout N.

Cyberpornography: Time Use,

Perceived Addiction, Sexual

Functioning, and Sexual Satisfaction.

Cyberpsychology Behav Soc Netw.

2016;19: 649-655.

doi:10.1089/cyber.2016.0364

54. Gouvernet B, Rebelo T, Sebbe F, Hentati Y, Yougbaré S, Combaluzier S, et al. Is pornography pathogen by itself? Study of the role of attachment profiles on the relationship between pornography and sexual satisfaction. Sexologies. 2017;26: e27-e33. doi:10.1016/j.sexol.2016.10.002

55. Wright PJ, Miezan E, Sun C. Pornography Consumption and Sexual Satisfaction in a Korean Sample. J Media Psychol. 2019;31: 164-169. doi:10.1027/1864-1105/a000246

56. Daspe M-È, Vaillancourt-Morel M-P, Lussier Y, Sabourin S, Ferron A. When Pornography Use Feels Out of Control: The Moderation Effect of Relationship and Sexual Satisfaction. J Sex Marital Ther. 2018;44: 343-353.

57. Bőthe B, Tóth-Király I, Bella N, Potenza MN, Demetrovics Z, Orosz G. Why do people watch pornography? The motivational basis of pornography use. Psychol Addict Behav J Soc Psychol Addict Behav. 2020. doi:10.1037/adb0000603

58. Ševčíková A, Blinka L, Škařupová K, Vašek D. Online Sex Addiction After 50: an Exploratory Study of Age-Related 
Vulnerability. Int J Ment Health Addict. 2020 [cited 17 May 2021].

doi:10.1007/s11469-019-00200-3

59. Grubbs JB. Commentary on Lewczuk et al (2020): Moral incongruence, disapproval and behavioral 'addiction.' Addiction. 2020;n/a. doi:https://doi.org/10.1111/add.15326

60. Grubbs JB, Perry SL, Wilt JA, Reid RC. Pornography problems due to moral incongruence: An integrative model with a systematic review and metaanalysis. Arch Sex Behav. 2019;48: 397415. doi:10.1007/s10508-018-1248-x

61. Štulhofer A, Wiessner C, Koletić G, Pietras L, Briken P. Religiosity, Perceived Effects of Pornography Use on Personal Sex Life, and Moral Incongruence: Insights from the German Health and Sexuality Survey (GeSiD). J Sex Res. 2021;0: 1-11. doi:10.1080/00224499.2021.1916422

62. Grubbs JB, Perry SL. Moral incongruence and pornography use: A critical review and integration. J Sex Res. 2019;56: 29-37. doi:10.1080/00224499.2018.1427204

63. Grubbs JB, Kraus SW, Perry SL, Lewczuk K, Gola M. Moral incongruence and compulsive sexual behavior: Results from cross-sectional interactions and parallel growth curve analyses. J Abnorm Psychol. 2020;129: 266-278. doi:10.1037/abn0000501

64. Brand M, Antons S, Wegmann E, Potenza MN. Theoretical Assumptions on Pornography Problems Due to Moral Incongruence and Mechanisms of
Addictive or Compulsive Use of Pornography: Are the Two "Conditions" as Theoretically Distinct as Suggested? Arch Sex Behav. 2019;48: 417-423. doi:10.1007/s10508-018-1293-5

65. Lewczuk K, Nowakowska I, Lewandowska K, Potenza MN, Gola M. Frequency of use, moral incongruence and religiosity and their relationships with self-perceived addiction to pornography, internet use, social networking and online gaming.

Addiction. 2020;n/a. doi:10.1111/add.15272

66. Charig R, Moghaddam NG, Dawson DL, Merdian HL, das Nair R. A lack of association between online pornography exposure, sexual functioning, and mental well-being. Sex Relatsh Ther. 2020;35: 258-281.

doi:10.1080/14681994.2020.1727874

67. Floyd CG, Landa S, Saunders MA, Volk F. The Moderating Influence of Moral Disapproval of Pornography on Couples' Sexual and Relationship Satisfaction. J Sex Marital Ther. 2020;0: 1-23. doi:10.1080/0092623X.2020.1783409

68. Hald GM, Stulhofer A, Lange T. Sexual Arousal and Sexually Explicit Media (SEM): Comparing Patterns of Sexual Arousal to SEM and Sexual SelfEvaluations and Satisfaction Across Gender and Sexual Orientation. Sex Med. 2018;6: 30-38. doi:10.1016/j.esxm.2017.11.001

69. Tóth-Király I, Vallerand RJ, Bőthe B, Rigó A, Orosz G. Examining sexual motivation profiles and their correlates using latent profile analysis. Personal 
Individ Differ. 2019;146: 76-86. doi:10.1016/j.paid.2019.04.002

70. Wright PJ, Bridges AJ, Sun C, Ezzell MB, Johnson JA. Personal Pornography Viewing and Sexual Satisfaction: A Quadratic Analysis. J Sex Marital Ther. 2018;44: 308-315. doi:10.1080/0092623X.2017.1377131
71. Wright PJ, Sun C, Steffen NJ, Tokunaga RS. Associative pathways between pornography consumption and reduced sexual satisfaction. Sex Relatsh Ther. 2019;34: 422-439. doi:10.1080/14681994.2017.1323076 
Table 1

Summary of all studies included in the present review

\begin{tabular}{lll}
\hline Study & Sample Characteristics & Key Outcomes \\
\hline (Barrada, Ruiz- & Cross-sectional sample of college & Physiological \\
Gómez, Correa, \& & students in Spain $(N=1,147 ;$ & sexual \\
Castro, 2019) & 30\% men; Mage $=21.08(2.0) ;$ & functioning; \\
[27] & 87.7\% heterosexual) & Sexual \\
& & satisfaction
\end{tabular}

(Bennett, LoPresti, McGloin, \& Denes, 2019)

[48]

(Berger, Kehoe, Doan, Crain, Klam, Marshall, \& Christman, 2019)

[31]
Cross sectional sample of U.S. undergraduate students in committed romantic relationships $(N=111 ; 65.8 \%$ men; $M$ age $=19.52$ (range: $18-$ 28); $94.6 \%$ heterosexual)

Cross-sectional survey of adults in the U.S. $(N=362$; Men: $n=$ $312 ;$ Mage $=30.7$ (5.9); $68.8 \%$ married, $2.9 \%$ engaged, $12.5 \%$ serious relationship, $5.5 \%$ casual relationship, $10.3 \%$ single; $97 \%$ heterosexual; Women: $n=48$; Mage = 28.1 (6.3); 60\% married, $4 \%$ engaged, $23 \%$ serious relationship, $6 \%$ casual relationship, $6 \%$ single; $81 \%$ heterosexual;
(Blais-Lecours,

Vaillancourt-Morel, Sabourin, \& Godbout, 2016)

[33]

(Bőthe, Tóth-Király, Bella, Potenza, Demetrovics, \& Orosz, 2020).
Cross-sectional sample of

Canadian adults $(N=832 ; 28.2 \%$

men; Mage = 25.2 (7.99); 35.3\%

married or cohabiting, $29.6 \%$

dating, 33.3\% single)

Cross-sectional samples of adults in Hungary (Sample 1: $N=772$; 49.5\% men; Mage = 22.6 (4.9); $51 \%$ single, $46 \%$ in a relationship, 2.3\% married;
Summary of Findings

Although most participants engaged in healthy OSA, compulsivity was associated with greater sexual functioning issues, higher sexual dissatisfaction, and higher desire for casual sex. Isolated sexual activities were associated with better sexual functioning and desire for casual sex.

Sexual satisfaction

Participants' sexual desire for their partners was not significantly affected by pornography use. Guilt over pornography use was negatively associated with participants' sexual desire for their partners.

Physiological sexual functioning

No relationship between pornography use and women's sexual functioning. For men, preference for pornography with masturbation was associated with erectile dysfunction. Erectile dysfunction rates were lowest for those who preferred partnered sex without pornography and increased significantly when pornography was preferred over partnered sex.

Physiological sexual functioning; Sexual satisfaction

Sexual satisfaction

Pornography use was indirectly associated with sexual dissatisfaction through perceived addiction and sexual dysfunction for both men and women.

Lack of sexual satisfaction was found to be a pornography use motivator, but it was not associated with FPU or 
[57]

(Bőthe, Tóth-Király, Demetrovics, \&

Orosz, 2017).

[37]

(Bőthe, Tóth-Király, Griffiths, Potenza,

Orosz, \&

Demetrovics, 2021).

[32]

(Bőthe, VaillancourtMorel, \& Bergeron, 2021)

[29]
80.4\% heterosexual; Sample 2: $N$

$=792 ; 53.9 \%$ men; Mage $=39.6$

(9.7); $20.4 \%$ single, $34.9 \%$ in a

relationship, $44.1 \%$ married;

79.5\% heterosexual; Sample 3: $N$

$=1,082 ; 50.4 \%$ men; Mage $=$

24.3 (5.4); 40.2\% single, $54.4 \%$

in a relationship, $5.4 \%$ married;

$82 \%$ heterosexual)

Cross-sectional sample of

Hungarian adults $(N=10,463$;

$70.5 \%$ men; Mage $=34.36$

(11.08); 100\% in any kind of

relationship)

Cross-sectional sample of adults

in Hungary $(N=14,581 ; 70.2 \%$

men; Mage $=33.58$ (10.95)

$82.7 \%$ heterosexual; $43.3 \%$ in a

relationship, $26.1 \%$ single, $4 \%$

engaged, 25\% married, $2.8 \%$

divorced, . .5\% widow/er, $1.5 \%$

other)

Cross-sectional study of mixedsex Canadian couples $(N=265$

couples; men's Mage = 31.49

(8.26); women's Mage $=29.36$

(6.74))
Sexual

satisfaction

hysiological

sexual

functioning

Physiological sexual functioning;

Sexual satisfaction
PPU, but it was associated with other pornography use motivators (e.g., sexual pleasure, sexual curiosity, emotional distraction/suppression, stress reduction, boredom avoidance, fantasies, and self-exploration).

Mindset about sex life malleability was a more important indicator of level of sexual satisfaction than PPU.

Frequency of pornography use was weakly and positively associated with sexual functioning in men and women. Self-reported problematic pornography use was negatively and weakly associated with sexual functioning.

Motivation to use pornography to avoid negative emotions was associated with lower sexual satisfaction and lower sexual functioning. Sexual curiosity motives to use pornography were associated with higher sexual satisfaction and sexual functioning. Partnered pornography use was associated with increased sexual functioning for women.

(Brown, Carroll, Yorgason, Busby, Willoughby, \& Larson, 2017).

[40]

Cross-sectional sample of married couples in the U.S. $(N=$ 326 couples; $50 \%$ men; men's Mage $=38.23$ (10.43); women's Mage $=36.16$ (9.88); 100\% heterosexual)

(Charig, Moghaddam, Dawson, Merdia, \& das Nair, 2020)
Sexual satisfaction

Physiological sexual functioning
Pornography use was negatively associated with each spouse's own sexual satisfaction. Wives' pornography use was positively related to the couples' sexual satisfaction.

Pornography had a functioning. negligible role in sexual
Cross-sectional sample of adults in the U.K. $(N=252 ; 29 \%$ men; Mage $=30.6$ (9.3); $20.6 \%$ single, $7.1 \%$ dating, $68.3 \%$ exclusive 


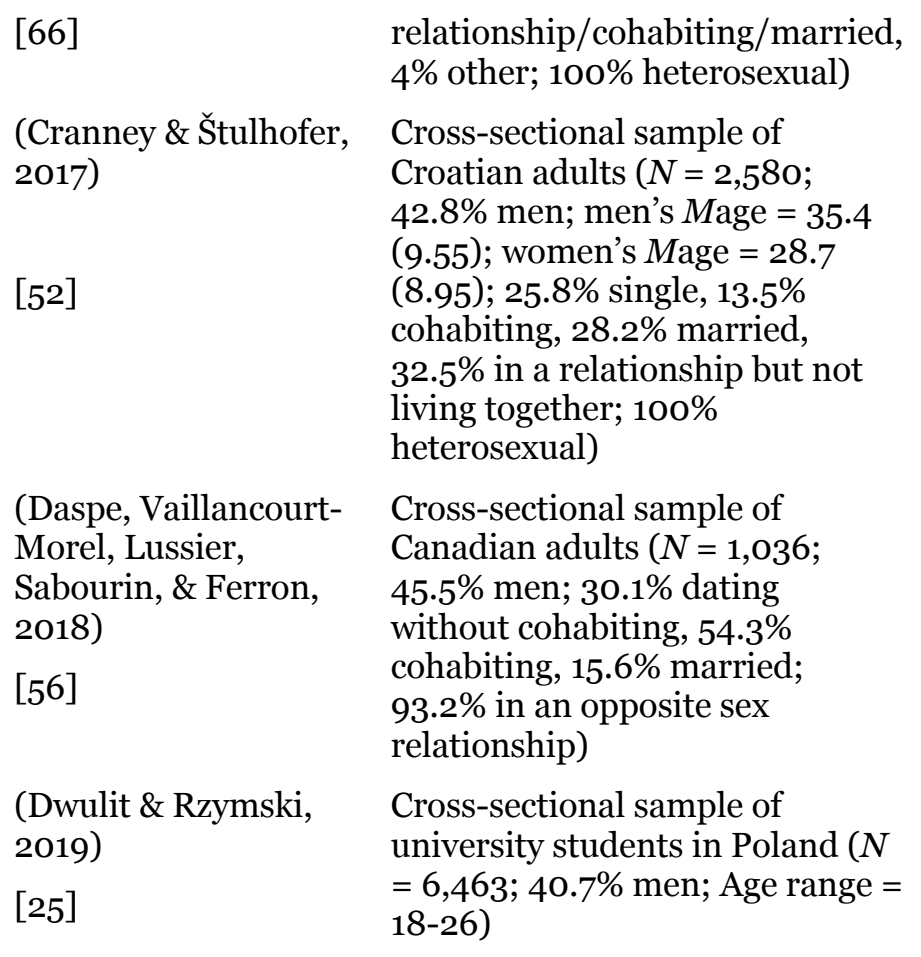

(Emmers-Sommer, 2018)

[42]

(Floyd, Landa, Saunders, \& Volk, 2020)

[67]

(French \& Hamilton, 2018)

[35]
Cross-sectional study of adults in the U.S. $(N=493 ; 44.6 \%$ men; $66.1 \%$ married/life partner, $33.9 \%$ monogamous dating relationship)
Cross-sectional sample of Canadian adults $(N=505$; Men: $n=195$; Mean age $=19.84(\mathrm{SD}=$ 2.7); $53.3 \%$ single, $11.8 \%$ casual sex, $10.8 \%$ dating, $28.7 \%$ long-
Sexual satisfaction

Sexual satisfaction

Physiological sexual functioning; Sexual satisfaction

Sexual satisfaction adults $(N=143$; current pornography users: $n=76$, age range: $18-26,40.7 \%$ men)
Sexual satisfaction
Sexual satisfaction was lower for religious women who watched both mainstream and nonmainstream pornography.

FPU was strongly associated with feeling out of control with pornography use when sexual satisfaction was lower.

Pornography use was not a problem for most participants. The most common self-perceived adverse effects of pornography use were need for longer stimulation and more sexual stimuli to reach orgasm and decreased sexual satisfaction.

Pornography was used solitarily for masturbatory purposes, which participants perceived to be physically sexually satisfying, but not psychologically sexually satisfying, for both themselves and their romantic partners.

The relationship between pornography use and couple satisfaction was mediated by sexual satisfaction. Moral incongruence over pornography use moderated this indirect relationship.

Positive effects of pornography on sex life included being female and viewing female-centric characteristics in 
term, 2.1\% cohabiting/married;

$84.6 \%$ heterosexual, $6.2 \%$

bisexual, $6.2 \%$ gay, $2.1 \%$

unlabeled, $1 \%$ other; Women: $n=$ 310 ; Mean age $=19.8(\mathrm{SD}=3.8)$;

$51.3 \%$ single, $8.8 \%$ casual sex, 8.4\% dating, 29\% long-term, $5.2 \%$ cohabiting/married; $84.2 \%$ heterosexual, $5.8 \%$ bisexual, 1.6\% lesbian, $4.5 \%$ unlabeled, $3.7 \%$ other)

(Gouvernet, Rebelo, Sebbe, Hentati, Yougbaré, Combaluzier, \& Rezrazi, 2017)

[54]

(Grubbs \& Gola, 2019)

[17]
Cross-sectional sample of French undergraduate students and community members $(N=590$; 23.7\% men; Mage = 24 (7.2))
Two cross-sectional samples (N1 $=147 ; \mathrm{N} 2=1,000$ ) and one longitudinal assessment $\left(\mathrm{N}_{3}=\right.$ 4,333) of adult men in the U.S.
Sexual satisfaction

Physiological sexual functioning
(Gutiérrez-Puertas, Márquez-Hernández, Gutiérrez-Puertas, Granados-Gámez, Carmen RodríguezGarcía, M., \& Aguilera-Manrique, 2020).

[41]

(Hald, Stulhofer, \& Lange, 2018)

[68]
Cross-sectional sample of Spanish university students $(N=$ 236; 24.2\% men; Mage $=22.08$ (4.99); 86.4\% single, $2.5 \%$ married, $11 \%$ other)
Sexual satisfaction pornography. Negative effects of pornography on sex life were associated with being male. Most participants reported no negative effects. The overall model indicated that pornography characteristics were not related to sexual satisfaction.

Pornography use did not impact the sex life of those with secure attachment styles, but it had a negative effect for those with anxious or avoidant attachment styles, and a positive effect for those with fearful attachment.

FPU was not consistently associated with sexual dysfunction crosssectionally or longitudinally. PPU was consistently associated with sexual dysfunction. Religiousness and moral incongruence over pornography use were highly correlated with PPU.

Participants who did not use pornography reported higher sexual satisfaction, particularly surrounding their sexual satisfaction with their partner and the amount of sexual activity they regularly engage in.
Cross-sectional survey of

Croatian adults $(N=2,035$;

41.8\% men; Mage = 30.75 (9.47); $47.6 \%$ in a relationship, $24 \%$ married, 28.4\% single; men: $68.9 \%$ heterosexual; women: $60.9 \%$ heterosexual)
Sexual satisfaction
No differences in sexual satisfaction were found between non-mainstream and mainstream pornography preference groups. 
Kowalewska, Kraus, Lew-Starowicz, Gustavsson, \& Gola, 2019)

\section{[50]}

(Leonhardt \&

Willoughby, 2019)

[49]

(McNabney, Hevesi, \& Rowland, 2020)

[24]

(Milas, Wright, \&

Štulhofer, 2020)

[22]

(Miller, McBain, Li, \& Raggat, 2019)

[43]
Cross-sectional survey of heterosexual Polish men (clinical: $N=72$; control: $N=$ 208)

Cross-sectional sample of adults in the U.S. $(N=858 ; 53.5 \%$ men; Mage $=33.1$ (9.36); $100 \%$ in a committed relationship; $54.08 \%$ first marriage, $17.37 \%$ cohabiting, $16.43 \%$ never married, $12.12 \%$ other; $89.98 \%$ heterosexual, $10.02 \%$ sexual minority)

Cross-sectional analysis of women from the U.S. and Hungary $(N=2,433 ; 85.4 \%$ heterosexual)

Longitudinal examination of Croatian adolescents $(N=1,289$; $39.9 \%$ boys; Mage (baseline) $=$ $15.9(.52)$

Cross-sectional sample of heterosexual men in multiple countries (study $1: N=326$; Mage = 27.63 (11.16); 31.3\% cohabiting, $73 \%$ in a relationship, not cohabiting; $46.3 \%$ not in a relationship; and in Australia (study 2: $N=335 ;$ Mage $=46.76$ (14.48); 89.3\% cohabiting, $10.7 \%$ in a relationship, not cohabiting)
Sexual satisfaction

Sexual satisfaction

Physiological sexual functioning

Sexual satisfaction

Sexual satisfaction
(Minarcik, Wetterneck, \& Short, 2016)

[36]
Cross-sectional sample of adults Sexual in the U.S. $(N=296 ; 25 \%$ men; Mage 28.51 (9.4); 100\% in a relationship: $38.1 \%$ married, $62.9 \%$ unmarried) satisfaction
There was a significant negative correlation between PPU and sexual satisfaction.

Pornography use was not associated with sexual satisfaction outcomes for women. For men, higher pornography use was related to lower satisfaction with sexual variety and time spent on intercourse.

FPU was associated with improved sexual responses during masturbation. FPU was not associated with overall sexual relationship satisfaction.

No relationship between FPU and sexual satisfaction initially or across time.

Pornography use frequency was associated with sexual dissatisfaction, preference for porn-like sex, and more frequent masturbation. Having a preference for porn-like sex was not related to lower sexual satisfaction, but frequency of masturbation was negatively, indirectly associated with sexual satisfaction

Sexual satisfaction was not significantly affected by pornography under any conditions, including those related to gender, use of pornography alone or with a partner or not at all, or based on frequency of pornography use. 
(Pepping, Cronin, Lyons, \& Caldwell, 2018)

[34]

(Perry \& Whitehead, 2019)

(Rodrigues, Lopes, Dawson, de Visser, \& Štulhofer, 2020)

[28]
Cross-sectional analyses of Australian adults (Sample 1: $N=$ 407; Mage = 38.49 (11.80);

$33.1 \%$ men; $100 \%$ in a long-term relationship; 93\% heterosexual;

Sample 2: $N=400$; $43 \%$ men;

Mage $=38.55$ (12.32); 100\%

single; $89.8 \%$ heterosexual)

Cross-sectional survey of U.S. adults $(N=1,501 ; 65 \%$ in a relationship; women: Mage = 49.96 (17.96); men: Mage = $49.45(18.32))$

Cross-sectional analysis of adults in Portugal $(N=866 ; 33.7 \%$ men; Mage $=27.4$ (8.58); 63.7\% monogamous, $24.25 \%$ nonconsensual non-monogamous (NCNM), $12 \%$ consensually nonmonogamous (CNM) ; 84.5\% heterosexual
Sexual

satisfaction

Sexual satisfaction

Physiological sexual functioning; Sexual satisfaction
(Ševčíková, Vašek, Blinka, Macháčková, \& Ježek, S, 2020)

(Sun, Bridges, Johnson, \& Ezzell, 2016)

[26]
Cross-sectional sample of Czech adults 50 years of age and older $(N=799 ; 54.5 \%$ men; Mage = 61.61 (7.94); 97\% heterosexual; Men: $93.35 \%$ in a relationship; Women: $88.71 \%$ in a relationship)

Cross-sectional study of heterosexual male university students in the U.S. $(N=487$; Mage $=19.98$ (1.88); $59.8 \%$ not in a relationship, $6.4 \%$ in a relationship but not monogamous, $28.5 \%$ committed

No relationship between sexual satisfaction and pornography related distress or excessive pornography use.

Pornography use was negatively associated with sexual satisfaction for religious men only, but not religious women or non-religious men.

Higher sexual satisfaction was associated with partnered pornography use for all groups. Partnered pornography use was also negatively associated with sexual arousal difficulties for monogamous individuals. Consenually nonmonogamous individuals used pornography substantially more than the other two groups but were as sexually satisfied as monogamous individuals. Nonconsensually nonmonogamous individuals reported the second highest amount of pornography use, the lowest levels of sexual satisfaction and the highest levels of sexual arousal difficulties.

Sexual satisfaction

Physiological sexual functioning; Sexual satisfaction
Sexual-life markers, such as satisfaction with sex frequency, the level of sexual desire, or absence of a relationship had no effect on the use of internet pornography.

Men's higher pornography use was associated with lack of enjoyment of partnered sexual activities, use of pornography during partnered sex, requesting 
relationship but not cohabiting, $2.5 \%$ cohabiting, $2.1 \%$ married) Vallerand, Bőthe, Rigó, \& Orosz, 2019)

[69]

Two cross-sectional studies of Hungarian adults $(N 1=679$; $29.2 \%$ single, $40.8 \%$ in a relationship; $N 2=632 ; 33.4 \%$ men; Mage = 26.02 (6.91); 26\%
(Tóth-Király, $33.4 \%$ men; Mage = 26.57 (7.39); single, $74 \%$ in a relationship)

(Vaillancourt-Morel, Blais-Lecours, Labadie, Bergeron, Sabourin, \& Godbout, 2017)

[33]
A cross-sectional study of 28.2\% men; Mage = 25.2 (8); $35.8 \%$ in a committed relationship (married or cohabiting), 29\% dating, 35.2\% single; $81.8 \%$ heterosexual) Canadian adults $(N=830$;
Vaillancourt-Morel, Rosen, Štulhofer, Bosisio, \& Bergeron, 2021).

[30]

(Wéry \& Billieux, 2016)

[21]
Cross-sectional sample of

Canadian couples $(N=217$ couples; $41.2 \%$ men; $72.5 \%$ unmarried and living together, $27.5 \%$ married; $57.1 \%$

heterosexual, $11.4 \%$ bisexual, $16.8 \%$ homosexual, $8.5 \%$ queer, 4\% pansexual, $2.1 \%$ other)

Cross-sectional sample of men in Belgium $(N=434 ;$ Mage $=29.5$ (9.5); $5.1 \%$ never been in a relationship, $18.9 \%$ single (without occasional sexual partner), $16.4 \%$ single (with occasional sexual partner), particular sex acts from his partner, and thinking about pornography to maintain arousal during partnered sex.
Sexual satisfaction

Physiological sexual functioning; Sexual satisfaction
Self-determined sexual motivations were associated with sexual passion, sexual satisfaction, and positive emotions during sex, whereas findings related to non-self-determined sexual motivations showed opposite effects.

Recreational pornography users reported higher sexual satisfaction and lower dysfunction.

Compulsive users had lower sexual satisfaction and dysfunction. Highly distressed less active users were sexually less satisfied and reported less sexual compulsivity and more sexual dysfunction. Women and dyadic users were more likely to be recreational users. Men were more likely to be compulsive users, and solitary users were more likely to be in the highly distressed less active group.

Physiological sexual functioning;

Sexual satisfaction

Women's pornography use increased their physiological sexual responsiveness during later partnered sexual encounters. Solitary use of pornography on partnered sex days was also associated with increased parner distress, regardless of gender.

Physiological sexual functioning; Sexual satisfaction
Most (99\%) participants reported that pornography was an OSA they used. Problematic OSA use was related to solitary-arousal activities (e.g., using pornography 
$59.6 \%$ in a stable relationship; $89.2 \%$ heterosexual, $8.8 \%$

(Willoughby, Carroll, Busby, \& Brown, 2016)

[47]

(Willoughby \&

Leonhardt, 2020)

[39]

(Willoughby, Leonhardt, \&

Augustus, 2021)

[38]

(Wright, Bridges, Sun, Ezzell, \& Johnson, 2018)

[70]

(Wright, Herbenick, Paul, \& Tokunaga, 2021)

Cross-sectional study of 45.05\% boys; Mage $=16.97$ homosexual, $2.1 \%$ bisexual)
Cross-sectional sample of heterosexual couples in the U.S. $(N=1,755$ couples; Mage $=$ men: 28.8 (8.76), women: 27 (7.99); $100 \%$ in a relationship: $53 \%$ dating, 27\% cohabiting, 20\% married)

Cross-sectional survey of heterosexual couples in the U.S. $(N=240$ couples; $50 \%$ men; men: Mage = 34.7 (9.23); women: Mage = $32.86(8.81)$ )

Cross-sectional survey of heterosexual couples in the U.S. $(N=240$ couples; $50 \%$ men; men: Mage = 34.7 (9.03); women: Mage = 32.8 (9.03))
Cross-sectional analysis of heterosexual adults in the U.S. $(N=1,513 ; 38.5 \%$ men; Mage = 22.59 (8.03); 50\% in a romantic relationship)
Sexual satisfaction

Sexual satisfaction

Sexual satisfaction

Sexual satisfaction

Sexual satisfaction to masturbate alone) and being motivated by sexual dysfunction to engage in use.

Pornography use had an indirect, negative effect on sexual desire for women, such that women's sexual desire mediated the relationship between pornography use differences and sexual outcomes for both men and women. Greater pornography use differences were associated with lower female sexual desire.

Couple pornography use was associated with higher sexual satisfaction. Female pornography use was associated with higher female sexual desire, whereas male pornography use was associated with lower female sexual desire.

Female pornography use was associated with higher female sexual desire, whereas male pornography use was associated with lower female partner sexual desire and sexual satisfaction, but higher male sexual satisfaction. Religiousness had little impact on results.

There was a negative, curvilinear relationship between FPU and sexual satisfaction, such that viewing pornography more than once per month was associated with greater decreases in sexual satisfaction. adolescents in the U.S. $(N=91$; (1.13); 85\% heterosexual, 2.2\%
An indirect path between FPU and sexual satisfaction was revealed, which indicated that pornography use was 
[23]

(Wright, Miezan, \&

Sun, 2019)

[55]

(Wright, Paul, Herbenick, \&

Tokunaga, 2021)

[46]

(Wright, Steffen, \& Sun, 2019)

[45] homosexual, $12.09 \%$ bisexual; $100 \%$ in a relationship)

Cross-sectional study of heterosexual adults in South Korea $(N=818 ; 71,6 \%$ men; Mage = 24.37 (4.37); 53\% in a relationship)
Sexual satisfaction

Cross-sectional study of adults in the U.S. $(N=1,629 ; 49.78 \%$ men; Mage = 40.86 (11.54); $100 \%$ in a relationship; $93 \%$ heterosexual, 6.9\% lesbian, gay, bisexual, asexual, or something else)
Sexual satisfaction
Cross-sectional survey of heterosexual adults in England $(N=195 ; 38 \%$ men; Mage $=$ 30.14 (9.12); and Germany ( $N=$ $699 ; 49 \%$ men; Mage $=30.01$ (8.24))

Cross-sectional study of heterosexual German adults $(N=$ 405; 51.85\% men; Mage = 30.2 (8.33); 87\% in a relationship)
Sexual satisfaction

Sexual satisfaction associated with engaging in more dominant behaviors, which was associated with causing distance between the couple, which was negatively related to sexual satisfaction.

There was a negative, curvilinear relationship between FPU and sexual satisfaction, such that viewing pornography on occasion was associated with increased sexual satisfaction but doing so more often was associated with greater decreases in sexual satisfaction.

Path analyses supported a model where FPU is associated with conditioned arousal to pornography, which is related to both upward pornography comparisons (comparing one's own sex life to pornography) and preference for masturbation to pornography over partnered sex, which are both negatively associated with sexual satisfaction

Both samples showed a negative curvilinear relationship between FPU and sexual satisfaction when pornography was used once per month or more.

FPU was associated with perceiving pornography as a primary source of sexual information, masturbation to pornography over partnered sex and devaluation of sexual communication, which were both associated with less sexual satisfaction. 
FPU $=$ Frequency of Pornography Use

PPU $=$ Self-Reported Problematic Pornography Use

OSA = Online Sexual Activities 


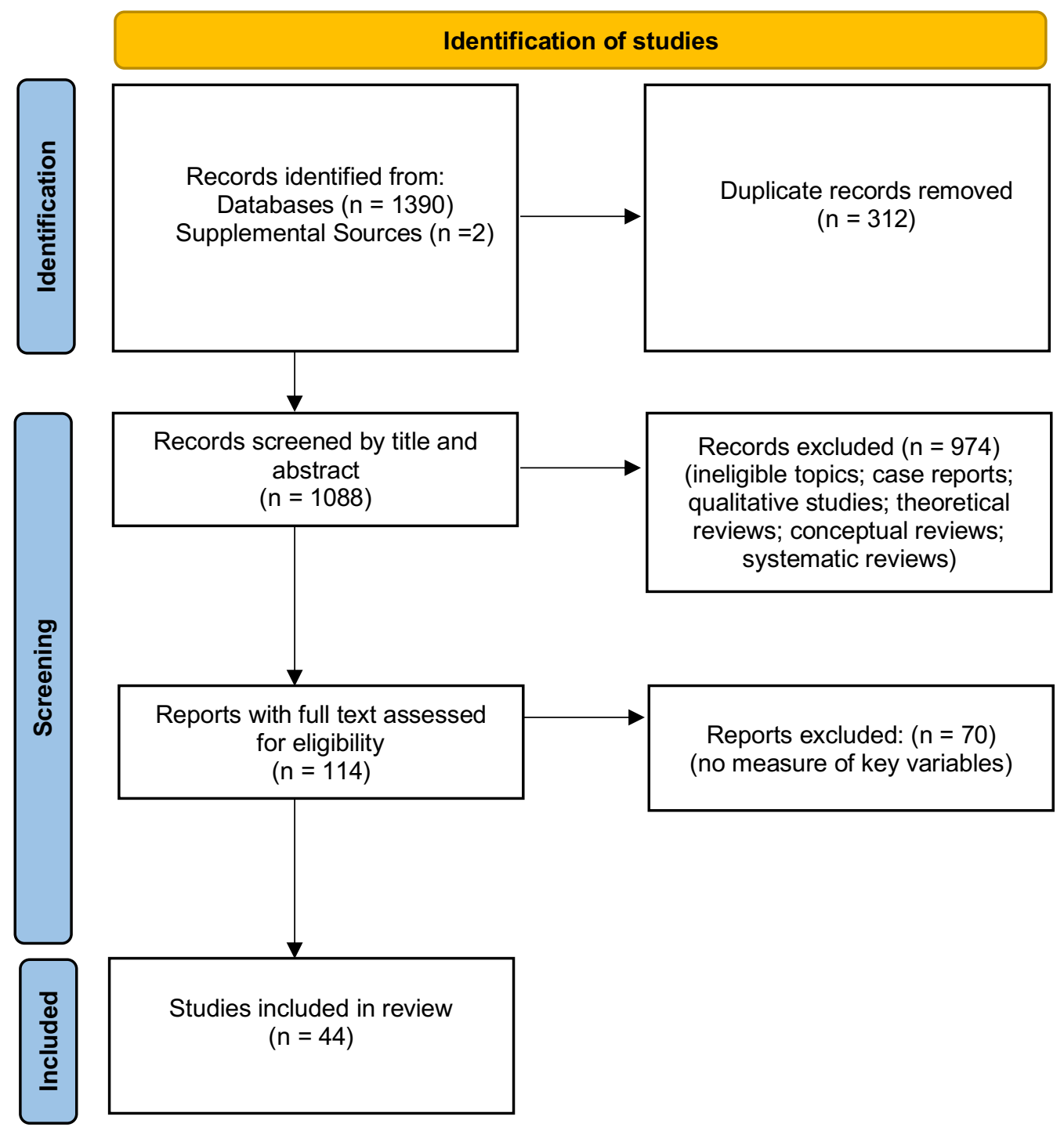

Figure 1. PRISMA flowchart detailing article search, screening, and inclusion process. 